\title{
Estrategias de financiarización en las producciones primarias de la Argentina durante los gobiernos del kirchnerismo (2003-2015) *
}

\author{
Lorenzo Cassini ${ }^{* *}$ \\ Gustavo García Zanotti *** \\ Martín Schorr ${ }^{* * * *, * * * *}$
}

\section{Resumen}

El presente trabajo aborda las estrategias de acumulación desplegadas en las actividades primarias en la Argentina en los años 2003-2015. Se trabaja el uso del excedente económico de dichos sectores al comparar su destino en el incremento de las capacidades productivas, la inversión financiera y la fuga de capitales, así como las transformaciones en la composición de los activos. Para ello se utilizó información agregada de toda la economía formal provista por la agencia de tributación argentina. También se abordaron estudios de casos con datos contables de las empresas más grandes. Se concluye que las estrategias de acumulación financiarizadas provocaron la subordinación de la inversión productiva a lógicas que priorizan tanto la preferencia por la liquidez como la fuga de capitales, causando un proceso de "reticencia inversora". Por lo tanto, se discute la función de estos sectores primarios como promotores del desarrollo económico nacional, tal como se postula desde distintas esferas.

Palabras-claves: Cadenas globales de valor; Financiarización; Uso del excedente; Producciones primarias; Argentina; Kirchnerismo.

\section{Resumo}

Estratégias de financeirização nas produções primárias da Argentina durante os governos do kirchnerismo (2003-2015)

Este trabalho aborda as estratégias de acumulação aplicadas nas atividades primárias na Argentina, nos anos 20032015. Trabalha-se a utilização do excedente econômico dos setores referidos ao comparar sua destinação no aumento das capacidades produtivas, o investimento financeiro e a fuga de capitais, assim como as transformações na composição dos ativos. Para isso, utilizou-se informação agregada de toda a economia formal, fornecida pela agência de tributação argentina. Também são abordados estudos de casos com dados contáveis das maiores empresas. Conclui-se que as estratégias de acumulação financeirizadas provocaram a subordinação do investimento produtivo a lógicas que priorizam tanto a preferência pela liquidez quanto a fuga de capitais, provocando um processo de "reticência investidora". Portanto, discute-se a função destes setores primários como promotores do desenvolvimento econômico nacional, tal como postulado pelas diferentes esferas.

Palavras-chave: Cadeias globais de valor; Financeirização; Utilização de excedente; Produções primárias; Argentina; Kirchnerismo.

\footnotetext{
*Artículo recibido el 29 de Mayo de 2018 y aprobado el 14 de Junio de 2019.

** Docente Universitario en Universidad Nacional de San Martín, San Martín, Provincia de Buenos Aires, Argentina. Email: 1cassini@unsam.edu.ar. ORCID: https://orcid.org/0000-0001-9307-2721.

*** Docente Universitario en Universidad Nacional de Rosario, Rosario, Argentina. E-mail: gustavo.d.garcia89@gmail.com. ORCID: https://orcid.org/0000-0001-6452-7010.

${ }^{* * * *}$ Docente Universitario en Universidad Nacional de Buenos Aires, Buenos Aires, Argentina. E-mail: schorr.mar@gmail.com. ORCID: https://orcid.org/0000-0002-2403-5449.

${ }^{* * * * * *}$ Investigador en Instituto de Altos Estudios Sociales / Consejo Nacional de Investigaciones Científicas y Técnicas (IDAES/Conicet), Buenos Aires, Argentina.
} 


\begin{abstract}
Financialization of firms strategies in argentine primary production during the kirchnerist governments (2003-2015)

This paper analyzes the accumulation strategies of primary producers in Argentina from 2003 to 2015 . We compare the economic surplus of these sectors and how it is used to increase productive capacities, financial investment and capital flight, as well as changes in the composition of assets. We use aggregate data on the whole formal economy provided by the Argentine tax agency. Accounting data from the primary sectors' largest companies is also presented. We conclude that because firms have financialized accumulation strategies, productive investment is subordinated to strategies that prioritize liquidity and capital flight, causing a process of "investment reticence". Therefore, we discuss the role of these primary sectors in promoting national economic development, as is suggested by different economic perspectives.
\end{abstract}

Keywords: Global value chains; Financialization; Use of surplus; Primary production; Argentina, Kirchnerism. JEL M21, O12, O13.

\title{
Introducción
}

Desde hace unos años, tanto a nivel conceptual como en lo alusivo a las propuestas de intervención, ha ido ganando un protagonismo creciente la noción de "cadenas globales de valor" (CGV). En última instancia, lo que se desprende de este concepto nuevo es algo similar de lo que se seguía (y se sigue) del viejo postulado ricardiano: la mejor especialización productiva y la inserción internacional más eficiente para los países es la que resulta de jerarquizar las ventajas comparativas existentes, que en el caso de la Argentina se corresponde centralmente con sectores basados en recursos naturales.

De modo estilizado, el enfoque de CGV plantea que, para países con abundancia de recursos naturales, la opción más viable, si no la única en tiempos de globalización, pasa por potenciar las redes basadas en recursos naturales como plataforma para el desarrollo. Se trata de una propuesta que ha logrado congregar un amplio y variado consenso a nivel latinoamericano y mundial ${ }^{1}$. En el caso argentino, y a modo de ejemplo, cabe traer a colación los señalamientos de un documento oficial en el que se presentan los lineamientos básicos sobre el perfil productivo deseable para el país de cara al año 2030: "los recursos naturales serán disparadores esenciales del desarrollo, tanto en la forma de alimentos sofisticados como en la posibilidad de que el campo sea motor de la industrialización mediante eslabonamientos hacia atrás, en software de precisión, máquinas, servicios profesionales y de logística, marcas país, etc." (Presidencia de la Nación, 2017).

En oposición a esta visión predominante existe una importante producción académica que realiza una multiplicidad de críticas fundadas al modelo de desarrollo basado en las cadenas o redes conformadas a partir de los sectores primarios. Desde diversas aproximaciones, estas investigaciones han arrojado luz sobre las consecuencias que un régimen de acumulación asentado sobre tales bases tiene en términos de, entre otros aspectos, el horizonte del crecimiento económico y la estabilidad macroeconómica, la estructura empresarial, las formas

(1) A título ilustrativo se remite a Bisang (2011), Fanelli (2011), Llach (2010), Marín (2016), Marín, Navas Alemán y Pérez (2013), Navajas (2011) y Pérez (2010). 
de producción y sus implicancias en términos tecnológicos, territoriales y medioambientales, la ocupación y los niveles salariales y distributivos, etc. ${ }^{2}$

Dentro de estos enfoques críticos hay una línea que, hasta el momento, no ha sido lo suficientemente desarrollada con basamento empírico: aquella que posa su mirada sobre las lógicas de acumulación que priorizan los actores predominantes en las actividades basadas en recursos naturales.

Al respecto, en la fase capitalista actual se evidencia una suerte de subordinación del capital productivo al financiero. A partir de esta constatación, han surgido numerosos estudios de los que se desprende como conclusión general la creciente financiarización de las economías y, más específicamente, de las estrategias de acumulación de las empresas, en especial de las que integran los segmentos más concentrados del capital ${ }^{3}$. Sin embargo, hasta el momento pocos trabajos han abordado específicamente la forma que asume la financiarización en los sectores primarios ${ }^{4}$.

En ese marco, y a partir de la recuperación de algunos aportes de la literatura sobre financiarización, el objetivo de este trabajo es aportar una serie de evidencias tendientes a captar ciertas especificidades del proceso de acumulación que se manifiesta en las producciones primarias de la Argentina durante los tres gobiernos del kirchnerismo (20032015). Se enfatiza en los sectores primarios porque constituyen la principal vía a través de la cual el país se inserta actualmente en las CGV y es al mismo tiempo la forma de inserción que este enfoque sugiere reforzar. La cobertura sectorial involucra al sector agropecuario, la producción minera, la hidrocarburífera y la industria alimenticia.

El objeto de estudio es abordado a partir del análisis de la evolución de indicadores que caracterizan la dinámica de acumulación de las empresas de los sectores seleccionados, haciendo hincapié en variables vinculadas a estrategias de financiarización. Los datos presentados están agregados sectorialmente y provienen de tres fuentes: Administración Federal de Ingresos Públicos (AFIP), Banco Central de la República Argentina (BCRA) y Comtrade. Esta información refiere a la economía registrada de la Argentina. Además, se buscó complementar el análisis al escoger a seis de las empresas más grandes del país en términos de

(2) Entre otras contribuciones sobresalen las de Chang y Lin (2009), Fernández (2017), Gorenstein (2018), Gudynas (2013), Gutman y Lavarello (2008), Puyana y Costantino (2012) y Svampa y Viale (2014). En una perspectiva crítica también se encuentran los aportes originales (sumamente vigentes) de Diamand (1973) y Fajnzylber (1983).

(3) Arceo (2011) enfatiza que en la faz actual del capitalismo el objetivo principal de las corporaciones es "independizar en la mayor medida posible los rendimientos de la propiedad, en tanto que título financiero, de la suerte del capital productivo específico que ha dado origen al título y genera el beneficio, y permitir así la máxima diversificación del riesgo. Esto supone, a su vez, para el capital productivo, la exigencia de adoptar una estrategia centrada en la maximización de la tasa de ganancia en el corto plazo... y debe para ello considerar, a fin de alcanzar la meta de rentabilidad deseada, todas las opciones, incluida la venta de activos fijos, la compra de activos financieros, la adquisición o la fusión con otras empresas, etc., si ello permite aumentar el precio de las acciones y los dividendos repartidos a los accionistas. El resultado es una modificación radical en la gestión de las empresas". En este texto y en la obra compilada por Chesnais (1999) se puede encontrar una sistematización bastante completa de los diferentes abordajes sobre financiarización.

(4) Al respecto, se destacan algunos trabajos que vinculan financiarización con reprimarización de economías emergentes, como los de Frenkel y Rapetti (2011), Gorenstein y Ortiz (2017) y Whittaker (2017), aunque desde aproximaciones analíticas diferentes a las contempladas en este estudio. 
facturación que se desenvuelven en distintos sectores primarios. Para ello se elaboró una serie de indicadores a partir de información contable de las mismas.

El texto se estructura de la siguiente manera: En la sección 1 se analiza la trayectoria de la rentabilidad y la inversión en sectores primarios con vistas a problematizar una cuestión para nada menor: la llamada "reticencia inversora". En la sección 2 se busca determinar los distintos usos del excedente que fueron priorizando los capitales que se desenvuelven en el ámbito de las producciones primarias de la Argentina. En la sección 3 se abordan los estudios de casos. Cierran el trabajo unas breves reflexiones finales.

\section{Rentabilidad e inversión en sectores vinculados a los recursos naturales y su procesamiento}

A partir de las preocupaciones analíticas planteadas en la introducción, en esta sección se problematiza la relación entre la tasa de rentabilidad y la de inversión en sectores abocados al procesamiento de recursos naturales. La relativa desconexión entre la evolución de ambas variables, que se expresa en una reducida reinversión de utilidades, ha sido problematizada desde diferentes aristas por varias investigaciones que analizan la dinámica de la acumulación del capital de las grandes empresas a escala global (Auvray; Dallery; Rigot, 2016; Krippner, 2005; Pérez Ártica, 2013; Serfati, 1999) y las especificidades del caso argentino (Azpiazu; Manzanelli, 2011; Cassini, 2015; Gaggero; Schorr; Wainer, 2014).

Dicho fenómeno tiene varias raíces y ha sido catalogado de diversas maneras: "reticencia inversora", "preferencia por la liquidez" o "exceso de ahorro". Una de sus causas más señaladas se asocia con la concentración y la centralización de los capitales. En tal sentido, se argumenta que las empresas líderes suelen funcionar con capacidad ociosa, de allí que ante un aumento de la demanda pueden incrementar sus niveles de producción sin necesidad de invertir grandes sumas de capital. En línea con lo anterior, se destaca la madurez tecnoproductiva de los capitales concentrados, así como el control oligopólico que suelen detentar y ejercer en una multiplicidad de mercados, de lo cual se desprenden relativamente bajas tasas de inversión para mantener posicionamientos competitivos.

En el caso argentino se ha caracterizado a la etapa que siguió al abandono del régimen de convertibilidad como un momento de recomposición de las condiciones de reproducción del capital (sobre todo de los segmentos más concentrados). Se trata de un fenómeno estrechamente asociado a la importante devaluación que marcó el fin del esquema de caja de conversión y que, entre otras cosas, implicó una declinación pronunciada de los salarios y de la participación de los asalariados en el ingreso.

En ese escenario, las tasas de inversión no acompañaron los importantes aumentos de rentabilidad que experimentaron las grandes corporaciones. En el caso específico de los sectores aquí estudiados, es insoslayable reparar en el hecho de que el período analizado coincide con una coyuntura internacional de precios y demanda sumamente favorable por

(5) Para los lectores interesados en las fuentes utilizadas, la metodología desplegada y la definición de las distintas variables empleadas en esta investigación, se remite al anexo que se presenta al final del trabajo. 
varios años, lo cual posicionó a los capitales que se desenvuelven en estos ámbitos productivos en el "podio de los ganadores" del planteo económico que se desplegó.

Otro elemento que condiciona la tasa de inversión es la fuga de capitales. Las evidencias disponibles indican que, en las últimas décadas, ante el auge de la financiarización a escala global, se han perfeccionado mecanismos financieros a través de salvoconductos en paraísos fiscales que permiten dirigir parte de los excedentes productivos para ser valorizados financieramente en el exterior (Gaggero; Rúa; Gaggero, 2013). Claramente las grandes empresas son las que poseen mayores mecanismos para lograr su cometido gracias a su influencia sobre varios renglones del balance de pagos. El hecho de que muchas de estas grandes empresas, más aún en los sectores primarios, sean de propiedad extranjera también impulsa la fuga de capitales por la remisión de utilidades a sus casas matrices y porque la estructura transnacional en la que se insertan les concede facilidades para sortear distintos tipos de restricciones cambiarias.

En el análisis de lo ocurrido durante el ciclo de gobiernos del kirchnerismo en la Argentina, diversos estudios han demostrado que, antes que apalancar procesos de ampliación del stock de capital, el incremento de la tasa y la masa de beneficios tuvo como contrapartida un salto notable en, por ejemplo, la fuga de capitales locales al exterior y la remisión de utilidades y dividendos, en ambos casos muy ligados a la operatoria del poder económico local (Manzanelli, 2016; Schorr; Wainer, 2017).

En estrecha relación con el punto anterior, algunos autores destacan como otro condicionante de la inversión reproductiva a la preferencia concedida por las grandes corporaciones a los activos líquidos. Puntualmente, en la fase capitalista actual los actores oligopólicos tienden a invertir en activos líquidos en busca de obtener ganancias con bajos niveles de riesgo. Esos beneficios pueden provenir tanto de la inversión en activos financieros, como en otros de carácter no financiero, pero que muchas veces se los utiliza como tales en la búsqueda de obtener ganancias patrimoniales a corto plazo para viabilizar ingentes y rápidas distribuciones de dividendos entre los accionistas. Así, se consuma una suerte de subordinación de los objetivos de las empresas productivas a las exigencias y la lógica del capital financiero $(\text { Arceo, 2011) })^{6}$.

Una vez reseñados los principales fundamentos económicos de la "reticencia inversora", en lo que sigue nos abocamos a estudiar la evolución bajo los gobiernos del kirchnerismo de la tasa de inversión y la de rentabilidad en el ámbito de las producciones primarias. Para ello, se considera la evolución de la inversión neta fija (o inversión productiva), los resultados operativos y los resultados financieros, todos en relación con el patrimonio neto para tener un denominador común que facilite comparaciones entre sectores y a lo largo del tiempo ${ }^{7}$.

(6) Los activos líquidos poseen una rotación acelerada en la cartera, por lo tanto, demandan financiamiento en forma permanente y compiten por el mismo con la inversión productiva.

(7) Con el fin de captar ciertos rasgos distintivos de los sectores estudiados, en la sistematización y la presentación del material estadístico que se analiza, se decidió incluir las tendencias del "resto de la economía". Este agregado surge de sustraerle 
Se dirá que existe "reticencia inversora" cuando se presente una disociación entre la inversión productiva y los resultados operativos a lo largo del tiempo. Tal discrepancia podría clasificarse en dos tipos: a) en el nivel de las tasas (toda vez que el margen de beneficios es considerablemente mayor que el de inversión) y b) en su evolución (cuando el coeficiente de rentabilidad aumenta con el tiempo, pero la formación neta de capital no acompaña dicho movimiento).

Los resultados de estas indagaciones quedan reflejados en el Gráfico 1. Desde esta perspectiva se comprueba que, en el período analizado, en todos los sectores procesadores de materias primas, lo mismo que en el resto de la economía doméstica, mejoró notablemente la capacidad de generar valor, así como la apropiación del mismo por parte del capital: la tasa de rentabilidad al final de la serie se encuentra holgadamente por encima de los registros correspondientes a $2003^{8}$.

\section{Gráfico 1}

Argentina. Evolución de la tasa de rentabilidad operativa y financiera y la tasa de inversión neta fija de los sectores vinculados a los recursos naturales y el resto de la economía (excluido el sector financiero), 2003-2015 (en porcentajes)

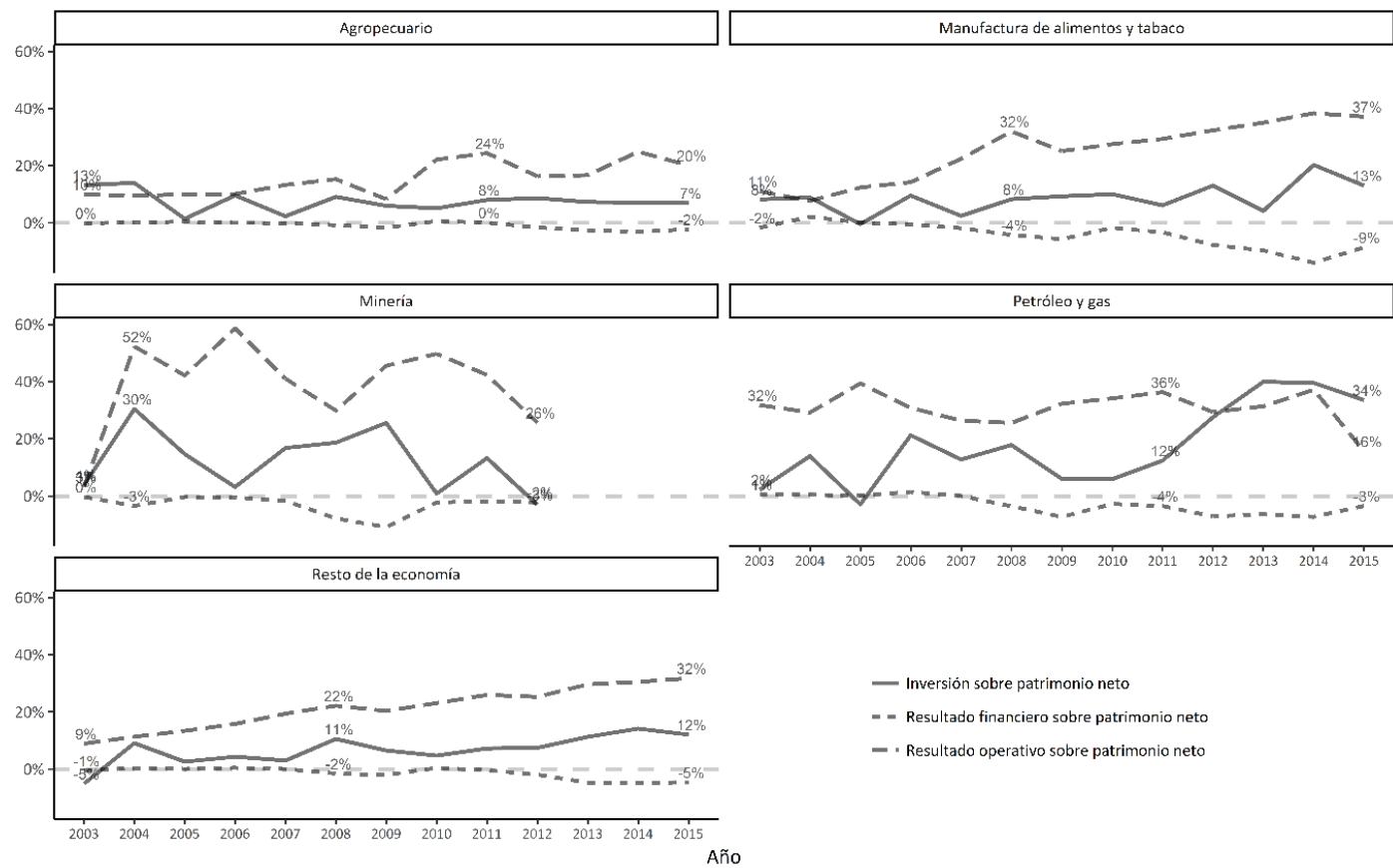

Fuente: Elaboración propia con datos de AFIP.

a los datos correspondientes al conjunto de las actividades económicas aquellos que pertenecen a los rubros analizados y al sector financiero (en este último caso por cuanto se trata de una actividad que posee un comportamiento bastante diferente a las restantes y porque uno de los propósitos del estudio es el de evaluar a los sectores procesadores de materias primas en términos relativos al resto de la economía real de la Argentina). Para más precisiones, véase el anexo metodológico.

(8) La única excepción la constituye el sector hidrocarburífero, cuya tasa media de rentabilidad cayó en 2015, fundamentalmente por efecto del desplome del valor del barril de petróleo a nivel internacional. 
Al focalizar el análisis en el sendero evolutivo de la inversión neta fija, se puede observar que en los rubros asociados al procesamiento de recursos naturales tuvieron lugar trayectorias heterogéneas: mientras que la actividad agropecuaria, la industria alimenticia y la minería cerraron el período con un ratio inversor próximo al de 2003, en el caso de la producción de hidrocarburos, los registros terminaron por ser superiores (sobre todo por lo ocurrido a partir de 2012). Más allá de las diferencias verificadas, en cada una de las producciones se corrobora que en la totalidad o en casi toda la etapa 2003-2015 las tasas de inversión productiva se ubicaron en niveles más reducidos que los márgenes de beneficios, lo cual es indicativo de que el fenómeno de la "reticencia inversora" fue más o menos intenso en estas ramas de actividad, lo mismo que en el resto de la economía nacional. Los resultados financieros son negativos en todos los sectores y se vuelven más negativos a lo largo de los años como consecuencia del endeudamiento creciente, aspecto que se aborda en la próxima sección.

Hechas estas consideraciones generales, cabe adentrarse en lo sucedido en cada sector. En la producción hidrocarburífera, a partir de la renacionalización parcial de YPF, consumada a mediados de 2012, y de la implementación de diferentes modalidades de transferencias de recursos para hacer frente al escenario de "crisis energética", la intervención del Estado nacional logró traccionar a la formación de capital en el sector. A tal punto que la tasa de inversión sobrepasó a la de rentabilidad, lo cual contrasta con la situación de los años previos en los que se aprecia una "reticencia inversora" ostensible".

En el sector minero, los datos que suministra el Gráfico 1 indican que la tasa de inversión tendió a acompañar a la de rentabilidad, pero se mantuvo sistemáticamente a la zaga (en ambos casos con un desempeño oscilante). En esta producción hay que resaltar que desde fines de la década de 2000, en forma contemporánea con un deterioro en los precios internacionales de varios minerales, tuvo lugar una retracción importante de la formación neta de capital, lo mismo que del margen de beneficios; no obstante, la brecha entre ambas variables siguió siendo marcada.

En tanto, en el ámbito agropecuario se aprecia cómo entre 2003 y 2015 la inversión neta se mantuvo en niveles próximos al $10 \%$ (con una leve tendencia declinante), en un escenario signado por un crecimiento importante del margen de ganancia. Es sobre todo a partir de 2010 cuando la distancia entre ambas variables se ensancha, dando cuenta de una creciente "reticencia inversora" en el sector.

Una situación parecida se pone de manifiesto al observar lo sucedido en la industria alimenticia. En este caso, entre los años analizados, la formación neta de capital tendió a mantenerse constante (con una ligera tendencia al alza), al tiempo que la rentabilidad se expandió de modo considerable y en forma casi sistemática. La discrepancia entre ambas

(9) Esa alteración en el sendero inversor sectorial está íntimamente asociado a la estrategia desplegada por YPF una vez concretado el proceso de reestatización parcial de su estructura accionaria, ya que la mayoría de las restantes empresas de la actividad mantuvieron una lógica de acumulación asentada en una escasa "vocación inversora" (Schorr et al., 2015). 
variables se ensancha a partir de 2007. En este sector los resultados financieros son los más negativos, en particular en los últimos años.

En definitiva, de esta primera tanda de evidencias resulta que la "reticencia inversora" es un fenómeno que, con intensidades diversas, se encuentra difundido entre los sectores abocados al procesamiento de materias primas en la Argentina. La escasa "vocación inversora" constatada en estos rubros que, por diferentes razones, formaron parte del elenco de "ganadores" del esquema económico desenvuelto durante los gobiernos del kirchnerismo, arroja algunos elementos de juicio interesantes para la discusión con aquellos sectores que postulan que la mejor opción para el país pasa por estructurar su estrategia de desarrollo y de inserción internacional con eje en sus ventajas comparativas ${ }^{10}$.

Ahora bien, la vigencia de tasas de reinversión de utilidades relativamente bajas en el contexto de una importante expansión en las condiciones para la acumulación y la reproducción ampliada del capital invita a reflexionar sobre los factores que concurren a explicar el nivel de recursos asignados a la formación neta de capital, lo mismo que sobre el destino del excedente que no se volcó a ampliar las capacidades de producción en los sectores económicos analizados. A eso nos abocamos en la sección que sigue.

\section{Usos del excedente en las producciones primarias}

\subsection{Perfil de la inversión y endeudamiento: entre lo productivo y lo financiero}

Como se aludió, una proporción no menor de los fondos destinados a la inversión en las empresas de sectores primarios puede estar siendo destinada a colocaciones financieras en lugar de ser canalizada hacia la formación neta de capital. De allí que resulte interesante analizar la evolución de la inversión productiva y la financiera en las diferentes actividades procesadoras de materias primas. Al mismo tiempo, la creciente "financiarización" del capital productivo induce a las empresas a priorizar el endeudamiento con terceros como forma de financiamiento, a fin de aumentar el retorno sobre el capital y favorecer a los intereses de los accionistas.

El Gráfico 2 refleja la evolución entre 2003 y 2015 de la inversión productiva y financiera y del endeudamiento, todas medidas en relación con el resultado operativo para facilitar el análisis comparado ${ }^{11}$.

(10) En este punto vale la pena recalcar un rasgo distintivo del perfil inversor característico de las producciones primarias: la tendencia a la importación de paquetes tecnológicos, con escasos aportes en lo que refiere a la generación y la difusión de desarrollos nacionales, todo lo cual agudiza la problemática de la dependencia tecnológica.

(11) La inversión financiera incluye, entre los renglones más importantes, los depósitos a plazo, la tenencia de derivados financieros y títulos, y la participación en fondos fiduciarios o fideicomisos y en otras sociedades. 
Gráfico 2

Argentina. Evolución del peso de la inversión productiva y la financiera y el endeudamiento en relación con el resultado operativo de los sectores vinculados a los recursos naturales y el resto de la economía (excluido el sector financiero), 2003-2015 (en porcentajes)

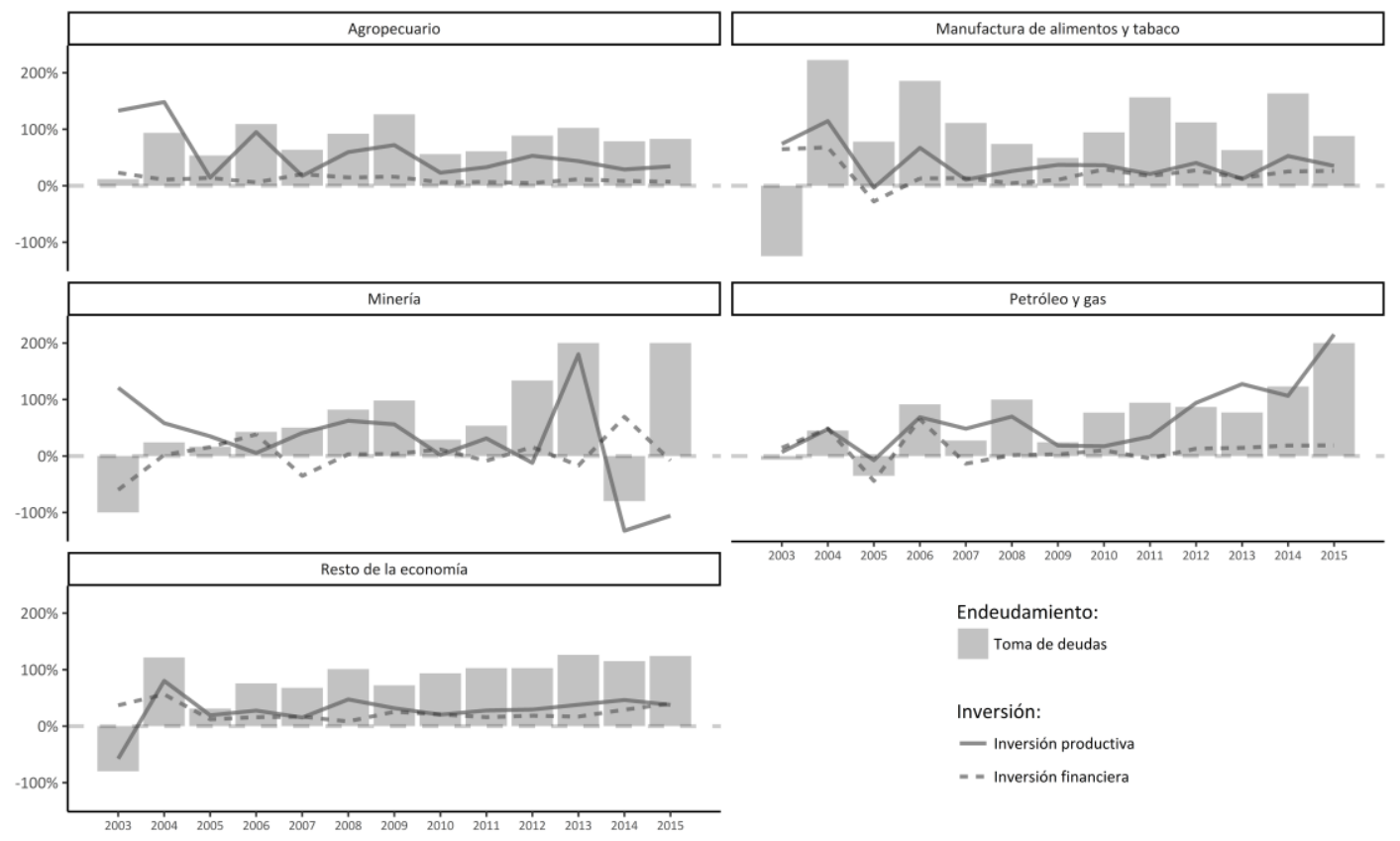

Fuente: Elaboración propia con datos de AFIP.

Una primera conclusión que surge de los datos presentados es que en todos los sectores el peso de la inversión productiva en las ganancias operativas generalmente supera al de la inversión financiera. Más aún, el endeudamiento supera los fondos destinados a ambos tipos de inversión en la mayoría de los años y sectores. Una parte del endeudamiento excedente corresponde a los fondos utilizados para reponer el capital depreciado de un año a otro, ya que la inversión neta fija no incluye las amortizaciones. Sin embargo, el endeudamiento excede con creces estos usos y, como se trata más abajo, se destina también a financiar activos de corto plazo y fuga de capitales.

Al observar la trayectoria de los indicadores para el "resto de la economía" se comprueba que en 2008 es cuando se registra la mayor concentración de la inversión con fines productivos, la cual desde entonces tiende a declinar hasta quedar casi igualada con la inversión financiera. A partir de 2011 la adquisición de activos financieros adquiere especial dinamismo. Esta suerte de creciente "financiarización del excedente" se encuentra estrechamente asociada a dos procesos concurrentes: por un lado, un virtual estancamiento de la formación neta de capital en un escenario de mayor rentabilidad (Gráfico 1); por otro lado, la implementación de restricciones legales a ciertos destinos del excedente en el marco de la reaparición de la problemática de la restricción externa (básicamente el llamado "cepo cambiario" y otras 
limitaciones a la adquisición y la disponibilidad de divisas). A su vez, el endeudamiento tiene una tendencia creciente a lo largo de todo el período y se acelera a partir de 2013.

En el caso de los sectores procesadores de materias primas, la industria alimenticia constituye el rubro en el que se presenta la mayor paridad entre el uso productivo y financiero de los excedentes. En ese marco, de la información presentada se colige que mientras la relación inversión productiva/resultado operativo tiende a estabilizarse desde mediados de la década pasada, el peso de los activos financieros manifiesta una senda expansiva, sobre todo a partir de 2011 (en 2015 la "financiarización" orilló el 30\% de los beneficios agregados). A raíz del control de cambios imperante, que restringió la remesa de fondos al exterior por parte de las empresas extranjeras con una amplia y difundida presencia en la actividad, el flujo de inversión extranjera directa aumentó debido a la reinversión de las utilidades que no se podían remitir. Sin embargo, se puede deducir que el destino de esos recursos fue, en buena medida, la utilización para la compra de distintos tipos de instrumentos financieros que les permitieron a las firmas disponer de fondos líquidos para enviarlos al exterior una vez que se levantaran las restricciones cambiarias ${ }^{12}$. En este sector el endeudamiento es fluctuante y supera largamente los fondos destinados a ambos tipos de inversión, de hecho es de las actividades que más se endeuda junto a la agropecuaria.

El sector hidrocarburífero es otro de los que presenta una alta propensión a utilizar los excedentes con fines financieros. Hasta 2012 la participación de la inversión financiera en el resultado operativo total de la actividad exhibió fuertes fluctuaciones y, de allí en adelante, se estabilizó en niveles relativamente elevados, hasta llegar a significar aproximadamente la quinta parte de las ganancias. Esta rama de actividad también se caracteriza por un rol destacado de corporaciones extranjeras, las que se vieron afectadas por los controles aludidos, dando lugar a una dinámica de "financiarización" similar a la detectada para la industria alimenticia y el "resto de la economía". A partir de ese año, y directamente asociado a la reorientación estratégica que experimentó YPF tras la reestatización parcial de su capital accionario, la inversión productiva se expandió de modo significativo. Si bien, como se vio en la sección 1, por esa vía se logró revertir en parte la baja formación neta de capital que venía caracterizando al sector, no se frenó la utilización de fondos para "apalancar" la compra de activos financieros.

Por su parte, entre 2003 y 2015 se asistió a una reducción en el "grado de financiarización" de la producción agropecuaria: entre esos años los recursos financieros pasaron de representar algo más del $20 \%$ del resultado operativo del sector al $7 \%$. El seguimiento de las estadísticas que constan en el Gráfico 2 pone de manifiesto la existencia de una suerte de punto de inflexión en el bienio 2008-2009, cuando el sector atravesó una coyuntura compleja por diversos motivos (conflicto entre el gobierno y las patronales

(12) De allí que no resulte casual el dinamismo que han venido experimentando la remesa de utilidades y dividendos y otros flujos asociados a la operatoria del capital extranjero radicado en el país una vez levantando el "cepo cambiario" a comienzos de la gestión de gobierno de "Cambiemos" (Cantamutto; Schorr, 2018). 
agropecuarias, sequía, crisis internacional). Hasta allí se evidenciaron los registros más elevados de inversión financiera (con picos del 20\%), que incluso en algunos años superó a la productiva. Desde entonces se constata un declive de ambos indicadores.

Finalmente, en el sector minero se aprecian muchas fluctuaciones en los dos coeficientes de inversión. En esa tendencia general, el principal hecho a destacar pasa por lo ocurrido a partir de 2012 cuando, en un escenario internacional signado por un deterioro importante en los precios, tuvo lugar un proceso bastante intenso de "desinversión productiva". Esto ocurrió, en buena medida, a raíz de una suba pronunciada en las amortizaciones frente a menores resultados operativos.

En suma, sobre la base de la "reticencia inversora", la principal conclusión de este apartado remite a que una parte del excedente generado en las actividades y apropiado por el capital tuvo por destino la toma de posiciones financieras. Sin embargo, la inversión productiva supera a la financiera en la casi todos los años y sectores. Es decir, los resultados que no tienen por finalidad inversión productiva ni financiera tienen otro destino que, como se verá, está muy asociado a la fuga de capitales. Una explicación de este fenómeno es el tamaño relativamente reducido que tiene el mercado financiero argentino que lo vuelve incapaz de absorber las ganancias generadas por las empresas.

\subsection{Excedente y fuga de capitales}

Además de la adquisición de activos financieros, otra estrategia de valorización priorizada por las grandes empresas es lo que se conoce como fuga de capitales. La misma puede realizarse a través de diferentes vías, como la compra de activos en el exterior (sea financieros -divisas, títulos, acciones, depósitos- o físicos -inversiones inmobiliarias y en empresas-), la remisión de utilidades y dividendos, los pagos de interese ${ }^{13}$ y el establecimiento de precios de transferencia a través de distintos procedimientos (sobrefacturación de importaciones, subfacturación de exportaciones, servicios de deuda generados por créditos intra-firma, etc.). Algunos de estos mecanismos implican maniobras de elusión o evasión fiscal y para su despliegue se suelen utilizar compañías constituidas en paraísos fiscales, donde los requerimientos de información e impositivos suelen ser mucho menos exigentes que en otras jurisdicciones. Así, la fuga de capitales no sólo socava la capacidad recaudatoria del Estado, sino que también condiciona sobremanera el resultado del balance de pagos en países como la Argentina.

Para realizar una estimación de mínima de la fuga de capitales se procedió a adicionar los montos correspondientes a los años 2003 a 2015 de tres de los mecanismos mencionados: la formación de activos externos (FAE), o sea, la compra de activos en el exterior por parte de residentes locales; los pagos en concepto de intereses y remisión de utilidades; y los precios de

\footnotetext{
(13) Se incluye el pago de intereses como mecanismo de fuga porque las empresas suelen recurrir a la toma de préstamos con empresas vinculadas en el exterior como una forma de girar utilidades. No obstante, una parte de los intereses pagados corresponde a préstamos "genuinos" que tienen por fin el financiamiento de la empresa.
} 
transferencia involucrados en el comercio exportador ${ }^{14}$. Los resultados de estos cálculos se vuelcan en el Gráfico 3, en el que también se incluye la significación de la inversión productiva, siempre en términos relativos al resultado operativo de cada actividad.

Gráfico 3

Argentina. Evolución de la inversión productiva y la fuga de capitales como porcentaje del resultado operativo de los sectores vinculados a los recursos naturales y el resto de la economía (excluido el sector financiero), 2003-2015 (en porcentajes)

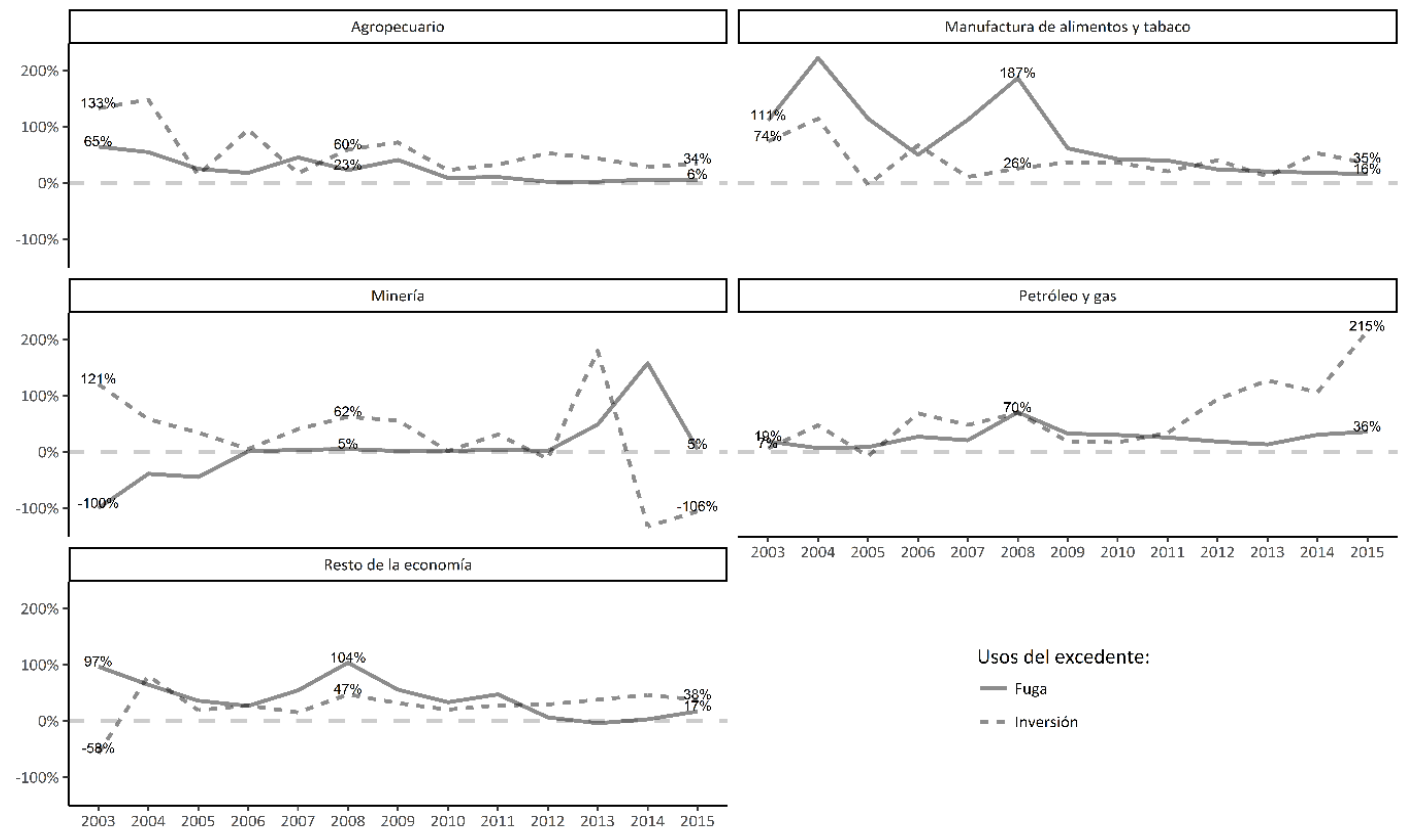

Fuente: Elaboración propia con datos de AFIP, BCRA y Comtrade.

Las evidencias con que se cuenta permiten afirmar que en el "resto de la economía" la fuga de capitales alcanzó los valores más elevados en los años en los que ocurrieron eventos asociados a cierta inestabilidad o incertidumbre económica y/o política, como la salida regresiva de la convertibilidad (2002 y 2003), el conflicto entre el gobierno nacional y las principales entidades que nuclean a los propietarios agropecuarios (2008), las repercusiones locales de la crisis internacional (2009) y momentos eleccionarios (2007 y 2011). La intensidad de la fuga se manifiesta en el hecho de que en varios años llegó a superar a los registros destinados a la inversión productiva de las empresas ${ }^{15}$. En ese marco, también se observa que, tomado en conjunto, en el período estudiado la fuga de capitales tendió a ser mayor en las

(14) Las precisiones metodológicas para la estimación de estos indicadores se pueden consultar en el anexo referido.

(15) A partir de 2011 la fuga de capitales tiende a reducirse por la implementación de los controles cambiarios que, entre otras cuestiones, limitaron el giro de utilidades al exterior y la compra de activos externos, al tiempo que volvieron más exigentes las obligaciones de liquidación de divisas para los exportadores, en particular de bienes primarios. 
producciones primarias que en el "resto de la economía", con la excepción de la minería, en la que tuvo lugar una trayectoria bastante errática.

En el ámbito de los sectores procesadores de materias primas, en un desempeño muy influido por las estrategias corporativas de las grandes firmas de la actividad (muchas de ellas pertenecientes a capitales extranjeros -véase la sección 3-), la industria alimenticia fue la que mostró los mayores niveles de fuga de capitales, en particular hasta 2010. Al respecto, cabe incorporar dos observaciones. Primero, en casi todos los años previos a la puesta en práctica de los controles cambiarios, la salida de divisas en esta rama de actividad superó los montos destinados a la inversión. Segundo, el flujo de fuga de capitales se redujo parcialmente con la entrada en vigor de las restricciones cambiarias (llegó a representar cerca del $20 \%$ del excedente generado en la actividad), lo cual evidencia que las empresas encontraron algunos mecanismos para sortear esos límites. En ese escenario, los excedentes que no pudieron remitirse al exterior no se usaron para financiar inversiones productivas, sino que, como se analizó en el apartado anterior, se volcaron en parte a la toma de posiciones financieras. De modo que puede concluirse que las empresas alimenticias fueron especialmente dinámicas en lo que al despliegue de estrategias de valorización financiera se refiere, aun cuando se aplicaron ciertos controles sobre el uso de sus fondos.

En lo que se refiere al rubro agropecuario, la fuga de excedentes al exterior fue inferior que la de la producción alimenticia, aunque hasta 2009 asumió cierta relevancia y superó en un par de años a los recursos destinados a ampliar el stock de capital de la actividad. Una vez establecido el control de cambios se aprecia que, a diferencia de lo ocurrido en las manufacturas de alimentos, las firmas del sector no tuvieron tanta capacidad para sortear las restricciones, fenómeno que seguramente se deriva de la menor presencia relativa de capitales foráneos en este ámbito.

En el caso de la producción hidrocarburífera se corrobora que también fue una actividad bastante dinámica en lo que se asocia con la salida de excedentes allende las fronteras nacionales. Hasta la reestatización parcial de YPF, y durante varios años, la canalización de recursos a la formación neta de capital fue inferior a los recursos enviados al exterior. Ahora bien, de la información sistematizada surge además que ni los controles cambiarios ni el "regreso del Estado" a la conducción de la empresa más grande del país posibilitaron aminorar la fuga de capitales, la que hacia el final de la serie comprometió algo más de la tercera parte de los beneficios sectoriales (una proporción que más que duplica a la que corresponde al "resto de la economía" argentina) $)^{16,17}$.

(16) En este punto hay que tener presente lo antedicho en cuanto a que con la reestatización parcial de YPF la compañía modificó la estrategia que había desplegado en los años anteriores, como resultado de lo cual aumentó de modo considerable sus inversiones productivas en detrimento de la fuga de capitales (conducta que fue acompañada por muy pocas empresas de la actividad). De ello se deduce que la vigencia de relativamente elevados coeficientes de "dolarización de los excedentes" se relaciona con el desempeño de buena parte del resto del oligopolio sectorial.

(17) Las evidencias presentadas indican que en 2003-2015 la minería evidenció bajos niveles de fuga de capitales (la única excepción es 2014, pero el indicador está influido por el bajo resultado operativo de la actividad). 
Una vez detectado que durante los gobiernos kirchneristas la mayoría de los sectores procesadores de materias primas fueron dinámicos en materia de fuga de capitales, vale la pena analizar con detalle el sendero evolutivo de los diferentes componentes de esta variable (Gráfico 4).

\section{Gráfico 4}

Argentina. Evolución de los distintos componentes de la fuga de capitales como porcentaje del resultado operativo de los sectores vinculados a los recursos naturales y el resto de la economía (excluido el sector financiero), 2003-2015 (en porcentajes)

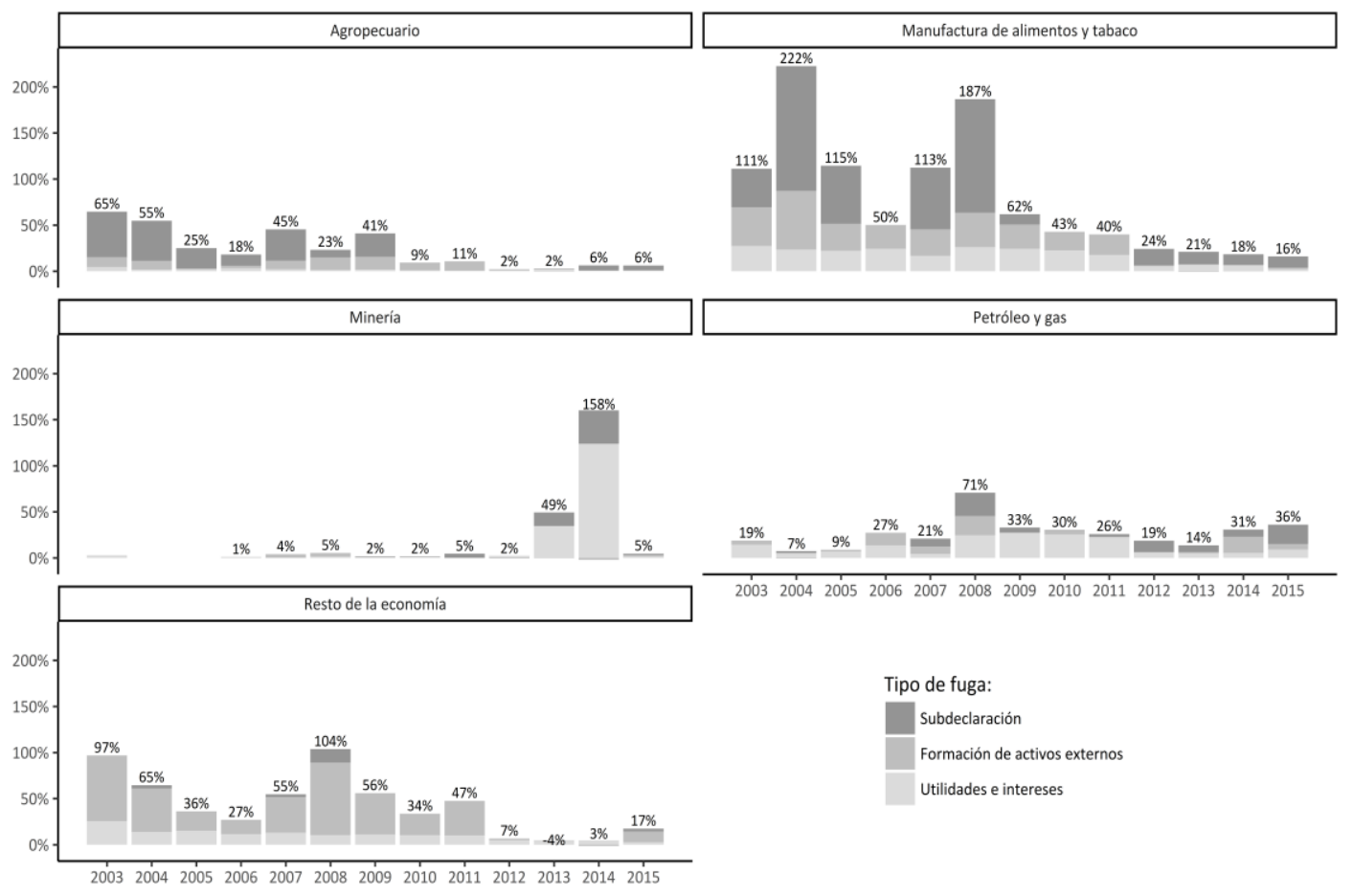

Fuente: Elaboración propia con datos de BCRA y Comtrade.

Al posar la mirada sobre el "resto de la economía" se verifica que la FAE fue la vía más relevante de la fuga de excedentes y que declina abruptamente tras la aplicación de las restricciones cambiarias. En segundo lugar se encuentra el renglón asociado a la remisión de utilidades y el pago de intereses, mientras que los precios de transferencia son los de menor participación relativa sobre las ganancias totales.

Dentro de las producciones primarias, la industria alimenticia fue la que más recurrió a los precios de transferencia como canal para la fuga de capitales. De hecho, en años como 2004, 2007 y 2008, este mecanismo representó más de la mitad de la salida de divisas que 
generaron las empresas de esta rama de la actividad económica ${ }^{18}$. Luego del pico máximo alcanzado en el año del "conflicto con el agro", la fuga por precios de transferencia declinó para retomar cierto protagonismo relativo entre 2012 y 2015: cuando las restricciones cambiarias imperantes limitaron la salida de excedentes al exterior por las otras vías, el establecimiento de precios de transferencia en el manejo del comercio exterior fue la vía priorizada.

En el ámbito agropecuario la composición de la fuga de capitales asume rasgos parecidos a los de la industria alimenticia, aunque involucrando proporciones menores del excedente sectorial. En este rubro también los precios de transferencia constituyen el principal andarivel para la salida de divisas, al tiempo que parecen actuar como una suerte de salvoconducto para la fuga en los años en los que estuvo vigente el control de cambios. Por su parte, en este sector la adquisición de activos en el exterior tiene una tendencia similar que en el "resto de la economía", mientras que las utilidades y los intereses presentan un menor peso relativo, ya que en esta rama no es tan marcada la presencia de capitales extranjeros (como sí lo son en las otras producciones analizadas).

En el caso de la producción de hidrocarburos, en el período estudiado la remisión de utilidades y los pagos en concepto de servicios de deuda constituyeron la principal vía para la fuga de capitales, alcanzando los mayores registros entre 2008 y $2011^{19}$. En los años posteriores este mecanismo pierde protagonismo ante el señalado cambio de estrategia empresarial de parte de YPF, que se suma al efecto de las restricciones legales a la compra de divisas. El manejo discrecional de los valores del comercio exportador ocupa el segundo lugar en cuanto a los carriles privilegiados en el sector, concentrándose fundamentalmente en el bienio 2007-2008 y luego de 2012.

Por último, en términos relativos al excedente generado, el sector minero presentó bajos niveles de fuga de capitales, excepto en los años 2013 y 2014 debido a que, a pesar de las restricciones cambiarias vigentes, el Banco Central le permitió a las empresas mineras girar dividendos al exterior.

En síntesis, los desarrollos analíticos de este apartado permiten concluir que en la etapa 2003-2015 la mayoría de las producciones primarias de la Argentina presentó niveles de fuga de capitales superiores a los de los restantes sectores de la economía real. Se trata de una comprobación relevante que arroja luz sobre una cuestión que no suele estar muy presente en los planteos de quienes sostienen que la mejor especialización posible para el país es aquella

(18) Como se trata en la sección 3, en 2008 la AFIP demandó a varias compañías por estas maniobras.

(19) En la explicación de esta tendencia asumieron un papel central dos cuestiones. En primer lugar, de modo destacado, las formas que asumió el ingreso del grupo local Petersen (familia Eskenazi) al capital accionario de YPF (a comienzos de 2008). La operación tuvo como marco la suscripción de un acuerdo entre los accionistas "por el cual se estableció, entre otras cuestiones, la adopción de una política de dividendos por la cual YPF distribuirá el 90\% de las utilidades como dividendos" (YPF, 2009). El diseño de la operatoria contemplaba un crédito por algo más de 1.000 millones de dólares realizado por Repsol a Petersen, el que sería abonado con las utilidades devengadas en los años posteriores. En segundo lugar, la política de YPF bajo control del holding español promovió la desinversión en el país en pos de su crecimiento y su posicionamiento en otros mercados (Repsol-YPF, 2011). 
que se ordena a partir de sus ventajas comparativas: como se vio, el aporte de divisas que estas actividades generan vía exportaciones se ve reducido en mayor o menor grado por la fuga de capitales al exterior que se genera por diversos carriles. Ello sin mencionar que una proporción considerable del excedente de las firmas no tiene por destino la ampliación de las capacidades de producción, sino la adquisición de activos financieros ${ }^{20}$.

\subsection{Composición de los activos}

La caracterización de las estrategias de acumulación de los sectores basados en recursos naturales no puede obviar un breve repaso por la composición del activo de las compañías que se desenvuelven en los diferentes espacios productivos (Gráfico 5).

\section{Gráfico 5}

Argentina. Evolución de la composición de los activos de las empresas de los sectores vinculados a los recursos naturales y el resto de la economía (excluido el sector financiero), 2003-2015 (en porcentajes)
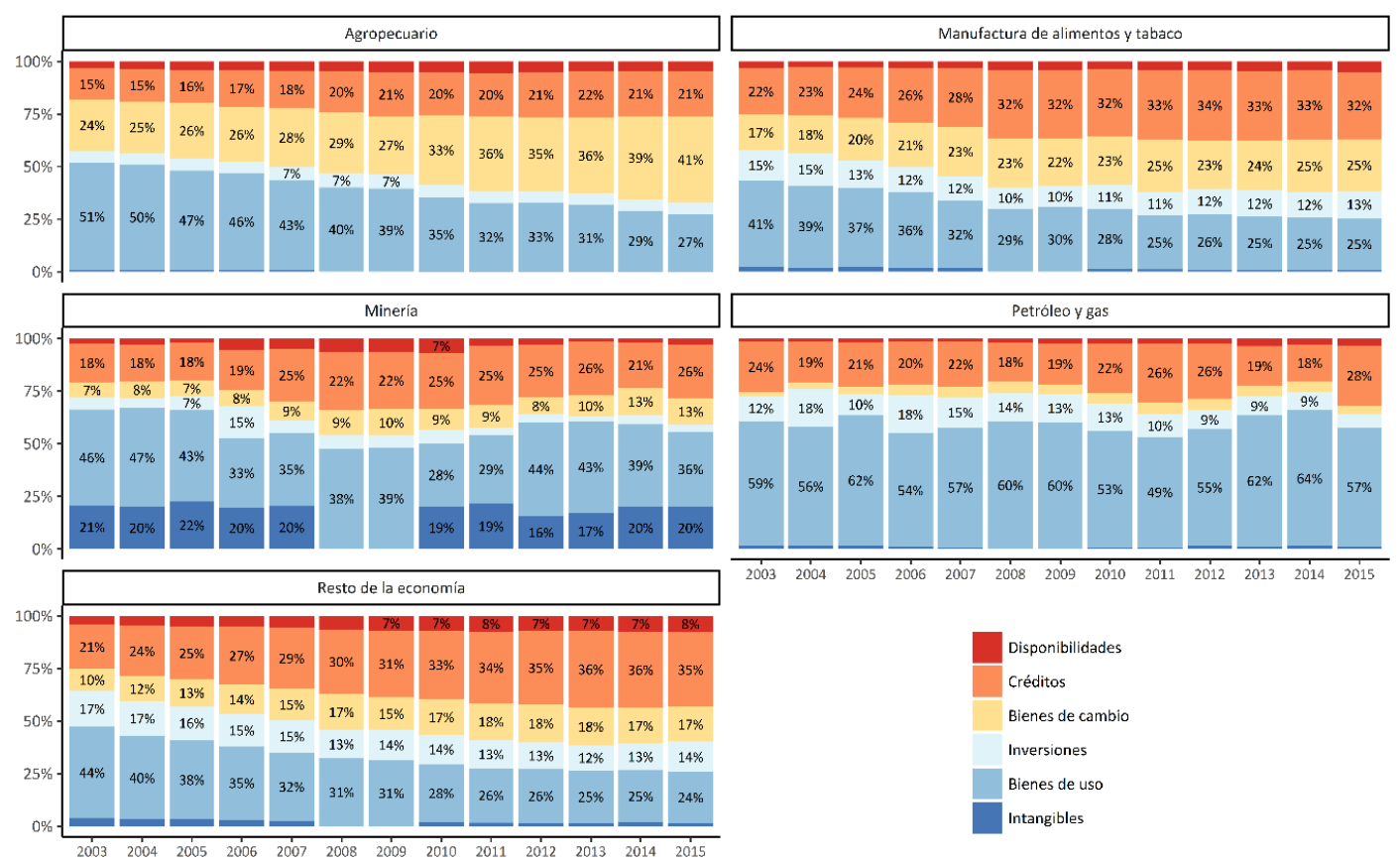

Disponibilidades

Créditos

Bienes de cambio

Inversiones

Bienes de uso

Intangibles

Fuente: Elaboración propia con datos de AFIP.

(20) En una economía como la argentina, con déficits recurrentes en el sector externo y en el fiscal, lo detectado en cuanto a la importancia que las empresas (lógicamente las de mayor envergadura) le suelen conceder a la remesa de utilidades, el pago de intereses y el establecimiento de precios de transferencia constituye, sin lugar a dudas, un problema de primer orden. En particular, vale remarcar que, si no se los controla en forma adecuada, los precios de transferencia son un mecanismo muy útil para que las firmas eludan eventuales controles cambiarios y, en paralelo, el pago de impuestos en el país. 
Dentro de las actividades primarias, cabe destacar que la producción hidrocarburífera y la minera tuvieron una composición más estable de sus activos en los años estudiados. En estos ámbitos el principal hecho a resaltar pasa por la importancia que asumen los bienes de uso dentro del activo total de las firmas, lo cual es un resultado previsible dada la naturaleza de los procesos productivos involucrados (importantes stocks de capital fijo).

En las empresas agropecuarias, hacia 2003 el principal rubro del activo son los bienes de uso, pero este ítem pierde representación a lo largo del período para ser superado por los bienes de cambio, proceso que se explica por diversos factores.

La forma de gerenciar las empresas agropecuarias fue cambiando a partir de la creciente injerencia del denominado "agro-negocio", que minimiza riesgos mediante la gestión flexible de los recursos productivos. Este modelo de negocios reduce los requerimientos de capital alquilando las tierras que explota y subcontratando servicios, al tiempo que disminuye la cantidad de tierras y maquinaria propia. El arrendamiento de tierras otorga flexibilidad para alcanzar el área de explotación óptima de acuerdo con la demanda esperada para la temporada, sin necesidad de inmovilizar capital (Arbeletche; Coppola; Paladino, 2012).

Al mismo tiempo, los bienes de cambio aumentan su participación en el activo porque las inversiones realizadas y los avances tecnológicos ampliaron la capacidad de almacenamiento de la cosecha, que es utilizada por las empresas para obtener ganancias especulando con el precio internacional de las materias primas y el nivel del tipo de cambio. En las empresas ganaderas, los bienes de cambio aumentan a partir de 2010 cuando el ciclo ganadero inicia una fase de retención en conjunción con un aumento del precio de la carne.

Dentro de la actividad agropecuaria, el otro rubro del activo que crece en importancia son los créditos. Al respecto, se pueden identificar dos tipos de empresas agropecuarias: las que son únicamente productoras y las productoras-distribuidoras, que comercializan también mercaderías adquiridas a otros productores. El aumento de los créditos en el activo del sector agropecuario se vincula con el comercio exterior de las distribuidoras, ya que parte de las exportaciones son a pago financiado. También responde a que estas empresas proveen insumos tales como semillas y productos químicos a los productores durante la pre-campaña y con pago diferido hasta el momento de la cosecha. El hecho de que los productores recurran al financiamiento de este tipo de empresas puede explicarse en parte porque el reducido sistema financiero argentino no ofrece opciones adecuadas y suficientes.

Por último, la información que proporciona el Gráfico 5 permite inferir que la estructura del activo de las empresas que se desenvuelven en la industria alimenticia exhibe una dinámica similar a la de las del sector agropecuario, con marcada tendencia declinante de los bienes de uso, pero en este caso con una expansión de los créditos y luego de los bienes de cambio. Como se apuntó, el avance crediticio se asocia a las exportaciones de estas firmas: se trata de firmas que exportan las materias primas procesadas y algunas también combinan esa actividad con la exportación de granos. 
Así, se puede concluir que el rasgo más saliente de la comercialización y el procesamiento de materias primas agropecuarias pasa por una retracción de la inversión en capital fijo, la búsqueda por minimizar riesgos y la acumulación de stocks con un criterio especulativo.

\section{Estudios de caso}

Con el objetivo de complementar y enriquecer los análisis que anteceden, en esta sección se evalúa la utilización del excedente económico y la dinámica de la inversión a nivel de empresa en algunas actividades ligadas a los recursos naturales. Para ello se estudiaron los balances contables de seis de las firmas más grandes de los sectores abordados (con la excepción del minero por falta de datos). Se trata de Cargill S.A.C.I. (Cargill), LDC Argentina S.A. (Dreyfus), Molinos Río de la Plata S.A. (Molinos), Cresud S.A.C.I.F. y A. (Cresud), YPF S.A. (YPF) y Pan American Energy (PAE).

Cargill, Dreyfus y Molinos se encuentran insertas en el sector de oleaginosas y cereales, el cual abarca tanto la producción como la comercialización de granos y aceites vegetales, biocombustibles, etc. Además, dentro de las actividades de Cargill y Molinos se incluye a la producción de alimentos elaborados (fideos, arroz, yerba mate, harinas y aceites, entre otros). Por su parte, Cresud se aboca a la producción agropecuaria a través de las más de 700 mil hectáreas que concentra en la Argentina ${ }^{21}$. Finalmente, YPF y PAE $^{22}$ se desenvuelven en el ámbito hidrocarburífero, siendo YPF la empresa más grande del mercado, secundada por PAE.

Las compañías que integran la muestra se desempeñan en rubros que fueron muy dinámicos en distintos tramos del ciclo kirchnerista y, como se comprobó, que acumularon un excedente económico considerable. La utilización del mismo implicó diversas trayectorias en cada una de las firmas; ello, a raíz de determinantes macroeconómicos, sectoriales e incluso microeconómicos. Para avanzar en la caracterización de tal heterogeneidad, en el Gráfico 6 se sistematiza información procedente de los balances contables de las empresas y se compara la inversión neta fija con la fuga de capitales al exterior (en ambos casos respecto de los resultados operativos).

(21) Se tomaron los balances individuales de la empresa dado que dentro de los consolidados se encuentra un amplio abanico de actividades.

(22) Comprende una asociación liderada por British Petroleum, con una participación minoritaria de Bridas Corporation (un joint venture entre el grupo Bulgheroni y la corporación china CNOOC Limited). 
Gráfico 6

Evolución de la inversión productiva y la fuga de capitales como porcentaje del resultado operativo de una muestra de empresas, 2003-2015 (en porcentajes)

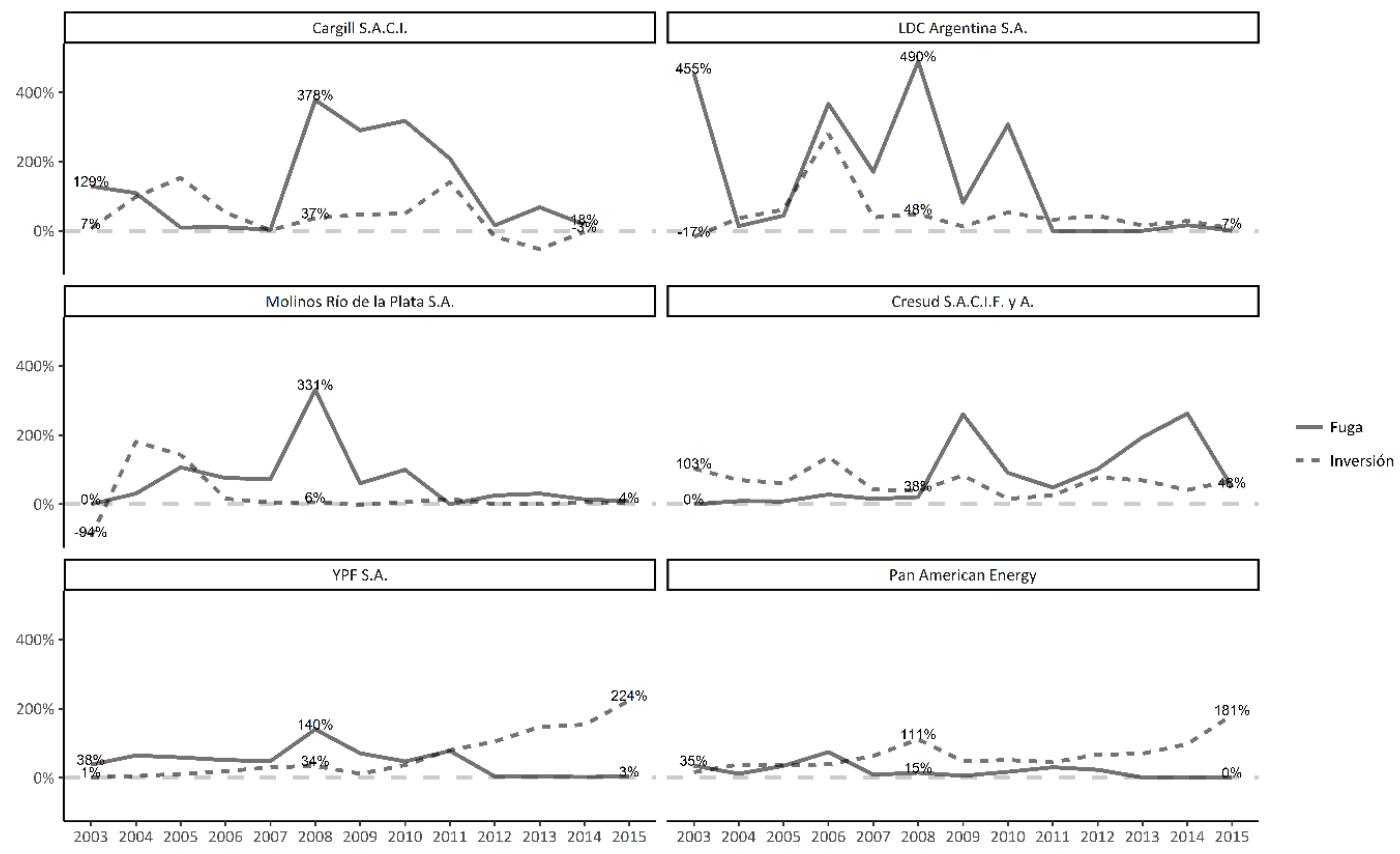

Fuente: Elaboración propia con datos de los balances contables.

Tanto Cargill como Dreyfus (las dos controladas por capitales extranjeros) aumentaron sus capacidades productivas en una primera etapa (2003-2006). En estos años el excedente económico apropiado por las empresas se incrementó, lo cual les permitió fugar capitales y en simultáneo invertir en la ampliación de sus respectivas dotaciones de capital. En un segundo momento (2007-2011) pudieron incrementar sus capacidades de producción, pero luego de transitada la crisis internacional debido a que en esa coyuntura ambas compañías priorizaron la fuga de capitales por sobre una mayor formación neta de capital. Es decir, la inversión compitió con la fuga dado que las casas matrices demandaron liquidez en un momento de caída de las ventas a nivel internacional. Finalmente, durante una tercera etapa (2012-2015), la inversión reproductiva fue débil ${ }^{23}$. Se trata de un momento en el que ambas empresas se vieron afectadas por la caída de los precios internacionales, al punto que sus ventas totales y sus exportaciones sufrieron un retroceso marcado. En estos años el excedente económico apropiado por el capital se achicó, de allí que la inversión y la fuga de capitales se redujeran con respecto a los otros períodos. Sumado a esto, en esta etapa se implementaron los controles

(23) Incluso Cargill vio disminuir su capacidad productiva a partir de 2012 dado que las amortizaciones fueron mayores que las inversiones concretadas. 
en el mercado cambiario, los cuales condicionaron a las firmas en su afán de remitir excedentes al exterior.

En el caso de Molinos, la revisión de sus balances permite concluir que en los primeros años del gobierno de Néstor Kirchner (en especial en 2004 y 2005) incrementó su capacidad productiva $^{24}$, mientras que en los años restantes este tipo de inversión se desaceleró en forma pronunciada. Ese menor ritmo inversor se asocia al hecho de que en el segmento de los alimentos elaborados, en el que esta compañía perteneciente al grupo local Pérez Companc ${ }^{25}$ es líder, tuvo lugar un proceso de concentración vinculado al desarrollo de marcas, lo que implicó un mayor destino de recursos a áreas vinculadas con el marketing, antes que al incremento de la capacidad instalada. La información provista por el gráfico de referencia permite concluir además que en los primeros años el volumen de sus resultados operativos le permitió incrementar tanto las capacidades productivas como la remisión al exterior de parte del excedente, que en un segundo momento (particularmente entre 2007 y 2010) jerarquizó la fuga de capitales y que en una última fase (2011-2015) ambas variables se expandieron levemente.

Al focalizar la indagación en Cresud (propiedad del conglomerado nacional IRSA), se observa que la formación neta de capital se expandió en dos momentos: entre 2003 y 2006 y, con menor intensidad relativa, en 2012-2015. En este punto corresponde introducir algunas menciones metodológicas en torno a la medición de la inversión en bienes de uso, dado que este ítem incluye la adquisición de hectáreas de tierras productivas con destino a la producción agropecuaria ${ }^{26 / 27}$. Desde ya, la adquisición de tierras no genera un incremento general de las capacidades productivas, sino más bien un proceso de cambio de manos entre particulares. En ese marco, la compañía concentró sus esfuerzos en la compra de tierras en la primera etapa del período analizado, cuando su valor aún permanecía depreciado ${ }^{28}$.

En líneas con las tendencias detectadas en la sección anterior, tanto YPF como PAE evidenciaron una relativamente reducida inversión productiva hasta 2011 producto del intenso proceso de fuga de capitales que llevaron a cabo (sobre todo la firma controlada por entonces por Repsol). A partir de 2012, el Estado nacional delineó como política energética la expropiación y la reestatización parcial de YPF y la inversión centralizada en la explotación de Vaca Muerta, con el fin de sustituir las importaciones hidrocarburíferas. Esta formación se caracteriza por el empleo de nuevas técnicas de extracción (no convencionales) dado el tipo de

(24) En estos años Molinos puso en funcionamiento algunas marcas de alimentos elaborados, así como un nuevo puerto en la localidad santafesina de San Lorenzo.

(25) Si bien se trata de una empresa de capital nacional, la controlante de Molinos se radica en un paraíso fiscal en Delaware (EE.UU.).

(26) En 2003 Cresud era propietario de 436 mil hectáreas y en 2015 informó la tenencia de 754 mil hectáreas.

(27) Las tierras de campo poseen ritmos de depreciación mucho menores en comparación al resto de los bienes de uso, de modo que se magnifica la inversión neta fija por la naturaleza del bien adquirido.

(28) En su balance de 2016, Cresud destaca que la empresa posee una estrategia de acumulación tendiente a la compra de suelo barato con bajas o nulas capacidades productivas para su posterior acondicionamiento y mejora a través de la aplicación de tecnología de punta. Esto le permite al suelo apreciar su valor para su venta posterior. 
recurso. Para ello, se debió destinar ingentes recursos para adquirir la experiencia necesaria, además de celebrarse alianzas estratégicas con empresas extranjeras. En el caso de PAE también se observa en estos años una tendencia similar (declinación de la fuga de capitales y aumento de la formación neta de capital), pero los montos invertidos comprometen un porcentaje menor del excedente económico que en $\mathrm{YPF}^{29}$.

Dada la importancia y las implicancias diversas que tiene la "dolarización del excedente", vale la pena realizar una serie de precisiones al respecto.

En relación con los receptores de la fuga de capitales de las empresas mencionadas, se observa como denominador común la afluencia de recursos hacia filiales en paraísos fiscales o a países con menores cargas tributarias que la Argentina. Esas estructuras controlan, comercian o financian a las filiales radicadas en nuestro país; en consecuencia, la fuga de capitales asume la forma de dividendos girados, precios de transferencia en el comercio exterior, servicios adquiridos, formación de activos externos y pagos de intereses ${ }^{30}$.

En lo que respecta a precios de transferencia, Molinos, Dreyfus y Cargill poseen reclamos de la AFIP por 571 millones de dólares, 469 millones y 89 millones, respectivamente. Estos valores poseen la particularidad de concentrarse en 2008. En cuanto a los socios comerciales que posibilitaron dichos sangrados de divisas, se remite a filiales en Chile para Molinos, en Suiza para Dreyfus y en Uruguay para Cargill.

En lo que alude a la formación de activos externos se destacan los casos de Dreyfus (309 millones de dólares), Molinos (165 millones) y Cargill (54 millones). Estos montos se concentraron nuevamente en 2008, coincidente con el lock-out de las patronales agropecuarias.

En el rubro de servicios adquiridos sobresalen los gastos de administración girados al extranjero por la sucursal argentina de Cargill (casi 100 millones de dólares entre 2004 y 2014), al tiempo que Dreyfus destinó alrededor de 10 millones por la adquisición de servicios a filiales afincadas en Suiza y los Países Bajos. Una estrategia similar desplegó la YPF controlada por Repsol: en el período 2003-2011 erogó en concepto de servicios procedentes de España una cifra superior a los 1.000 millones de dólares.

En materia de intereses pagados a filiales del mismo holding propietario radicadas en paraísos fiscales, de las evidencias disponibles se resaltan los casos de YPF (bajo la gestión de Repsol remitió a los Países Bajos una cifra cercana a los 30 millones de dólares), Dreyfus (circa 30 millones al Reino Unido y los Países Bajos) y Cargill (más de 20 millones).

(29) Si bien, como se vio, la fuga de capitales en el sector hidrocarburífero tendió a declinar a partir de 2012, la necesidad de financiamiento para la explotación de un nuevo tipo de recurso se incrementó exponencialmente. En el caso de YPF, en 2013 se concretó un contrato de financiamiento con Chevron, a través de salvoconductos en paraísos fiscales. Los intereses pagados por parte de YPF no forman parte de la fuga de capitales de la empresa propiamente dicha, sino del sector en general, y del capital extranjero en particular.

(30) Los datos que se consignan a continuación surgen de los propios balances contables, los reclamos de la AFIP en cobros de impuestos a las ganancias y filtraciones por la compra de divisas para el giro hacia el exterior. 
En lo que refiere al giro de utilidades y dividendos hacia las estructuras controlantes se destacan los siguientes casos: YPF con casi 13 mil millones dólares entre 2003-2011 concentrados hacia la casa matriz de Repsol en España; PAE con transferencias por 2.000 millones $^{31}$; Cargill con remesas próximas a los 1.100 millones (periodo 2003-2014) ${ }^{32}$; Molinos con giros por 428 millones, destinados a su controlante en Delaware; Cresud, que distribuyó dividendos por 127 millones dirigidas a la red empresas de la familia Elsztain en Uruguay, Islas Bermudas e Islas Caimán; y Dreyfus, que destinó 107 millones hacia su controlante en Suiza.

Una última dimensión de análisis sobre las estrategias de las empresas estudiadas remite a la evolución de la estructura de sus activos en la etapa 2003-2015 (Gráfico 7).

Gráfico 7

Evolución de la composición de los activos de una muestra de empresas, 2003-2015 (en porcentajes)
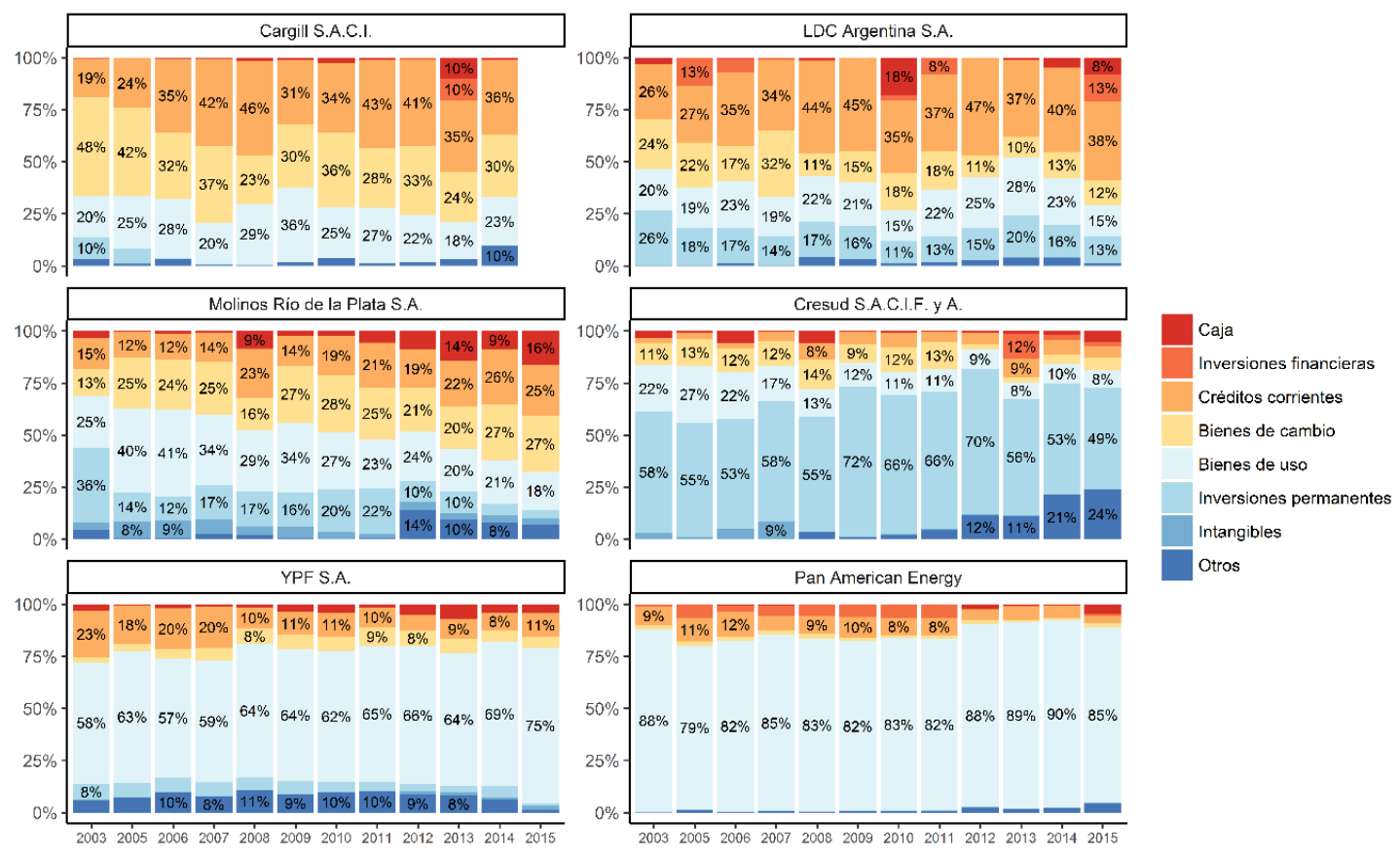

Fuente: Elaboración propia con datos de los balances contables.

Cargill, Molinos y Dreyfus poseen la particularidad de haber incrementado a lo largo de la serie la incidencia de ciertos rubros ligados a activos líquidos. Tanto en Cargill como en Dreyfus, el peso relativo de los créditos corrientes aumentó en forma considerable. Esta

(31) La asociación que conforma PAE se encuentra controlada de parte de British Petroleum por estructuras radicadas Delaware, mientras que Bridas Corporation posee presencia en las Islas Vírgenes Británicas.

(32) Cargill es controlada por una filial en Canadá. En los últimos años se ha revelado información producto de los denominados "Panamá Papers" por la cual las agencias de servicios corporativos recomiendan a sus clientes la apertura de filiales en ese país producto de numerosos tratados bilaterales de tributación que posee, los cuales incluyen a los paraísos fiscales. 
variable incluye en su mayoría a los préstamos otorgados a partes relacionadas, de los cuales se destacan los créditos por ventas y los financieros. De ello se infiere que el comercio exterior y su financiamiento por parte de las filiales argentinas resultan prioritarias en las respectivas estrategias de acumulación.

Los datos presentados sugieren que en el caso de Molinos los bienes de cambio aumentaron su ponderación de modo destacado, y que en Cargill y Dreyfus dicho rubro posee un importante peso relativo. De esta forma, las empresas retienen los bienes producidos para realizar ganancias patrimoniales al apreciar su valor a lo largo del tiempo. Estas ganancias no resultaron depreciables dependiendo el año tratado y llegaron a superar el 50\% de las ganancias brutas por la actividad principal.

En contrapartida, la gravitación de los bienes de uso fue decayendo notablemente en Molinos, al tiempo que en Cargill este ítem se retrajo desde 2009 y en Dreyfus no se observa una tendencia concluyente. En los tres casos, la participación de los bienes de uso representó poco más del $20 \%$ de los activos totales, mientras que los rubros que aluden a una mayor liquidez superaron esa significación o se ubicaron en umbrales aproximados.

Al respecto, las evidencias presentadas permiten identificar ciertos años con elevada liquidez que se refleja en el ítem de caja y en inversiones financieras. Por ejemplo, en Cargill la sumatoria del rubro caja e inversiones financieras superó a los bienes de uso en 2013; lo propio ocurrió con Dreyfus en 2010 y 2015; en el caso de Molinos se aprecia cómo el rubro caja fue aumentando con el tiempo hasta alcanzar el 16\% de los activos frente al 18\% de los bienes de uso. Así, en los últimos años analizados estas empresas líderes de la producción agroindustrial decidieron priorizar una mayor liquidez, en lugar de volcar recursos a la inversión neta.

La revisión de la información contable de Cresud lleva a concluir que esta firma posee una clara estrategia de acumulación anclada en su consolidación como holding. En otras palabras, la empresa se dedica a la adquisición de participaciones en sociedades fomentando una estrategia de diversificación de sus actividades, a raíz de lo cual en la Argentina cuenta con presencia en sectores tan diversos como la actividad comercial, la bancaria, la turística y la agrícola. En 2015 adquirió un grupo empresario israelí (con actividad en dicho país), por lo que sus ingresos se quintuplicaron y se diversificó hacia segmentos como el comercio minorista, los seguros, las telecomunicaciones y la distribución de agroquímicos. Además, en 2012 creó un fondo común de inversión en las Islas Bermudas con activos por más de 500 millones de dólares.

Finalmente, en la actividad petrolera los bienes de uso resultan preponderantes. Un aspecto interesante que surge de los balances de YPF y PAE es que con anterioridad a la reestatización parcial de la primera, en las dos se constataba un peso mayor de los créditos corrientes. 
En definitiva, al indagar sobre las características más salientes de las estrategias desplegadas en 2003-2015 por las empresas seleccionadas se reafirma lo constatado en el análisis sectorial: una lógica productiva con un componente importante de "reticencia inversora" y su correlato en la expansión de ciertas lógicas financieras (fuga de capitales hacia guaridas fiscales motorizada por una amplia gama de instrumentos, "preferencia por la liquidez", etc.).

\section{Reflexiones finales}

A lo largo de este trabajo se analizó un conjunto de evidencias tendientes a caracterizar las estrategias de acumulación desplegadas en ámbitos ligados a la explotación y el procesamiento de recursos naturales en la Argentina. Entre las principales conclusiones de las indagaciones realizadas se desprenden las siguientes.

En el período 2003-2015 las producciones primarias evidenciaron una "reticencia inversora" considerable. A instancias de la mejora en los precios (los internacionales y los relativos dentro de la economía doméstica), el excedente económico generado en estos espacios creció mucho más que la inversión productiva, de lo cual se sigue que, incluso en un contexto favorable, los sectores vinculados a los recursos naturales no tuvieron un "efecto derrame" amplio. La escasa "vocación inversora" fue particularmente intensa en la agricultura, la industria alimenticia y la actividad hidrocarburífera En la minería, por su parte, el fenómeno se hizo presente con más fuerza desde comienzos de la década de 2010 a partir de la retracción de los precios internacionales. El sector hidrocarburífero es el único que durante el período cubierto por este trabajo revierte este comportamiento reticente a la inversión y lo hace a partir de 2012 cuando es renacionalizada parcialmente YPF. Esta evidencia permite concluir que se requiere de una activa intervención estatal para que la inserción en cadenas globales de valor genere algún efecto dinamizador sobre la economía, en consonancia con la experiencia de otros países que utilizaron exitosamente ese tipo de inserción para impulsar su desarrollo (por ejemplo, Corea del Sur y China).

La contracara de la "reticencia inversora" fue la creciente inversión financiera, a la cual se direccionó una parte del excedente que no tuvo por destino la ampliación de las capacidades productivas. Con mayor o menor grado, en los rubros analizados se pudo constatar una estrategia de diversificación de cartera a partir de la incorporación de activos líquidos, proceso que se agudizó en los años que siguieron a las restricciones cambiarias que, entre otras cosas, restringieron la salida de divisas por diferentes canales. Las evidencias compiladas sugieren que los sectores primarios no se diferenciaron mayormente del resto de la economía argentina en lo que atañe al desvío de parte del excedente económico hacia usos financieros. De ello se sigue que, en lo referido a dinamizar el incremento en las capacidades de producción, a estos sectores no se les puede atribuir un elemento diferenciador, tal como hacen, por lo general sin mayores fundamentos, aquellos que postulan la importancia de estructurar la especialización productiva y la inserción internacional del país a partir de redes o cadenas globales basadas en 
recursos naturales. No obstante, el volumen de excedente sobrante luego de cubrir la inversión productiva es abultado y la inversión financiera sólo capta una fracción.

La acotada capacidad para absorber esos fondos que tiene el poco desarrollado sistema financiero doméstico, sumada a la recurrente inestabilidad macroeconómica, favorecen a que una de las principales formas que adquiere la financiarización de la economía argentina sea la fuga de capitales. De allí que no resulte casual que la salida de recursos al exterior por diferentes vías haya sido otro de los destinos del excedente económico de los sectores afincados en el procesamiento de materias primas que, al dominar varios renglones del balance cambiario, pudieron enviar ingentes recursos al exterior.

Precisamente, un elemento distintivo de las producciones estudiadas respecto del resto de la economía es su ostensible inserción comercial externa que les otorga acceso a divisas y una amplia gama de vías para la fuga estrechamente asociadas a su propia reproducción productiva y comercial, las cuales incluyen el establecimiento de precios de transferencia en el manejo del comercio exterior, el pago de intereses por préstamos intra-firma y la remisión de utilidades y dividendos, en muchos casos utilizando sociedades relacionadas en paraísos fiscales. Así, las facilidades para la fuga de capitales que tienen los sectores basados en recursos naturales por su propia dinámica productivo-sectorial agravan la restricción externa, aumentan la volatilidad macroeconómica y restringen el crecimiento económico de largo plazo. Las restricciones cambiaras aminoraron parcialmente la fuga, pero no implicaron que esos fondos se volcaran a la inversión productiva, tarea que sin duda requiere de políticas productivas activas y perdurables.

La composición de los activos es otro elemento para destacar. En su fase actual, la economía capitalista se caracteriza por la vigencia de un régimen de acumulación que jerarquiza rendimientos de corto plazo, a raíz de lo cual la cartera de los activos de las empresas tiende a volverse cada vez más líquida con miras a reducir el capital inmovilizado. Así, es habitual que dentro del total de activos ganen creciente ponderación rubros como las disponibilidades, los créditos otorgados, las inversiones financieras y los bienes de cambio, todos los cuales tienden a desplazar a los activos fijos. Al respecto, los datos analizados permiten concluir que en 2003-2015 los sectores procesadores de recursos naturales no escaparon a esta lógica de acumulación, sobre todo en la esfera agropecuaria y en la industria alimenticia: en ambos casos el "modelo de negocios" prioriza la rápida rotación de activos y la especulación con la fluctuación de los precios de los commodities y del tipo de cambio. Al mismo tiempo, las deficiencias del sector financiero local parecen ser cubiertas parcialmente por empresas productivas que otorgan financiamiento a clientes y proveedores, tal como refleja el aumento de los créditos otorgados. Por características tecno-productivas singulares, la minería y la rama hidrocarburífera son mucho más intensivas en activos fijos, lo cual no invalida la recurrencia a prácticas financieras por parte de las empresas con operatoria en tales esferas de la producción. 
En suma, de las especificidades que asume la dinámica de la acumulación y la reproducción del capital en los sectores estudiados resultan varios argumentos para cuestionar el supuesto virtuosismo que sus defensores le confieren al modelo de desarrollo basado en redes en torno de recursos naturales. Los relativamente bajos niveles de inversión productiva de estas actividades limitan la generación de eslabonamientos y capacidades tecnológicas locales. Muchos de los insumos son importados, lo mismo que los paquetes tecnológicos, por lo que generan escasos esfuerzos de innovación y encadenamientos virtuosos en el plano doméstico. La tecnología utilizada es mayormente de uso específico de estas actividades y no se traduce en mejoras en la competitividad para el resto de la economía. Tampoco se desarrollan eslabonamientos hacia adelante que transformen las exportaciones primarias en productos de mayor valor y conocimiento añadido, evidenciando las escasas oportunidades que ofrece este modo de participación en las cadenas globales de valor. Una proporción importante del excedente económico de estos sectores tiene como destino la fuga de capitales y la inversión financiera, recursos que obviamente no amplían las capacidades productivas del país.

Indudablemente, un modelo de desarrollo sostenible para un país con las características socio-económicas y demográficas de la Argentina requiere la captación de parte importante de ese excedente para uso productivo en sectores que resulten mucho más dinámicos en materia de, por ejemplo, la formación de capital, la generación y la dinamización de encadenamientos tecno-productivos y la creación de puestos de trabajo.

\section{Bibliografía}

ARBELETCHE, P.; COPPOLA, M.; PALADINO, C. Análisis del agro-negocio como forma de gestión empresarial en América del Sur: el caso uruguayo. Agrociencia Uruguay, v. 16, n. 2, 2012.

ARCEO, E. El largo camino a la crisis. Centro, periferia y transformaciones de la economía mundial. Cara o Ceca, 2011.

AUVRAY, T.; DALLERY, T.; RIGOT, S. L'entreprise liquidé. Le finance contre l'investissement. Michalon, 2016.

AZPIAZU, D.; MANZANELLI, P. Reinversión de utilidades y formación de capital en un grupo selecto de grandes firmas (1998-2009). Realidad Económica, n. 257, 2011.

BISANG, R. Agro y recursos naturales en la Argentina: ¿enfermedad maldita o desafío a la inteligencia colectiva? Boletín Informativo Techint, n. 336, 2011.

CANTAMUTTO, F.; SCHORR, M. El carácter social de Cambiemos. IDAES/UNSAM, 2018. Mimeo.

CASSINI, L. Reinversión de utilidades y concentración en la industria manufacturera argentina en la posconvertibilidad. Realidad Económica, n. 292, 2015. 
Estrategias de financiarización en las producciones primarias de la Argentina durante los gobiernos del kirchnerismo

CHANG, H.; LIN, A. Should industrial policy in developing countries conform to comparative advantage or defy it? Development Policy Review, n. 5, 2009.

CHESNAIS, F. (Comp.). La mundialización financiera. Génesis, costo y desafíos. Losada, 1999.

DIAMAND, M. Doctrinas económicas, desarrollo e independencia. Paidós, 1973.

FAJNZYLBER, F. La industrialización trunca de América Latina. Nueva Imagen, 1983.

FANELLI, J. Recursos naturales: ¿bendición o maldición? Sobre la experiencia argentina en los 2000. Boletín Informativo Techint, n. 336, 2011.

FERNÁNDEZ, V. La trilogía del erizo-zorro. Redes globales, trayectorias nacionales y dinámicas regionales desde la periferia. Anthropos/Ediciones UNL, 2017.

FRENKEL, R.; RAPETTI, M. Fragilidad externa o desindustrialización: ¿Cuál es la principal amenaza para América Latina en la próxima década? Cepal, Serie Macroeconomía del Desarrollo, 2011. (Documento de Trabajo, n. 116).

GAGGERO, A.; SCHORR, M.; WAINER, A. Restricción eterna. El poder económico durante el kirchnerismo. Futuro Anterior, 2014.

GAGGERO, J.; RÚA, M.; GAGGERO, A. Argentina. Fuga de capitales III (2002-2012). Magnitudes, vínculos, políticas e inercias estructurales. CEFID-AR, 2013. (Documento de Trabajo, n. 29).

GORENSTEIN, S. Recursos naturales, acumulación y desarrollo. Revisión del debate teórico en el capitalismo periférico. 2018. Mimeo.

GORENSTEIN, S.; ORTIZ, R. El nuevo ciclo de primarización en el Cono Sur latinoamericano. Revista Interdisciplinaria de Estudios Agrarios, n. 46, 2017.

GRONDONA, V.; BURGOS, M. Estimación de los precios de transferencia. El caso del complejo sojero. CEFID-AR, 2015. (Documento de Trabajo, n. 71).

GUDYNAS, E. Extracciones, extractivismos y extrahecciones. Un marco conceptual sobre la apropiación de recursos naturales. Observatorio del Desarrollo, n. 18, 2013.

GUTMAN, G.; LAVARELLO, P. Les industries agroalimentaires dans le contexte des nouvelles biotechnologies. Économies et Societés, n. 30, 2008.

KRIPPNER, G. The financialization of the American economy. Socio-Economic Review, n. 3, 2005 .

LLACH, J. Los desafíos productivos de la Argentina: ¿cuál es y cuál debería ser nuestro lugar en el nuevo mundo? Boletín Informativo Techint, n. 333, 2010.

MANZANELLI, P. Grandes corporaciones y formación de capital en la Argentina 20022012. Tesis (Doctorado)-Universidad de Buenos Aires. Facultad de Ciencias Sociales, 2016. 
MARÍN, A. Las industrias de recursos naturales como plataforma para el desarrollo de América Latina. In: DENZIN, C.; CABRERA, C. (Ed.). Nuevos enfoques para el desarrollo productivo. Estado, sustentabilidad y política industrial. Fundación Friedrich Ebert, 2016.

MARÍN, A.; NAVAS ALEMÁN, L.; PÉREZ, C. El posible rol dinámico de las redes basadas en recursos naturales para las estrategias de desarrollo en América Latina.In: DUTRÉNIT, G.; SUTZ, J. (Ed.). Sistemas de innovación para un desarrollo inclusivo. La experiencia latinoamericana. Foro Consultivo Científico y Tecnológico, 2013.

NAVAJAS, F. Energía, maldición de recursos naturales y enfermedad holandesa. Boletín Informativo Techint, n. 336, 2011.

PÉREZ, C. Dinamismo tecnológico e inclusión social en América Latina: una estrategia de desarrollo productivo basada en los recursos naturales. Revista de la Cepal, n. 100, 2010.

PÉREZ ÁRTICA, R. Acumulación de liquidez y exceso de ahorro en firmas de países desarrollados. Tesis (Doctorado)-Universidad Nacional del Sur. Facultad de Economía, 2013.

PRESIDENCIA DE LA NACIÓN. Argentina 2030. Jefatura de Gabinete de Ministros, 2017. Mimeo.

PUYANA, A.; COSTANTINO, A. Sojización y enfermedad holandesa en Argentina: ¿la maldición verde?", ponencia presentada en el Seminario "¿Cómo sembrar el desarrollo en América Latina?” organizado por la Universidad Autónoma de México, 2012.

REPSOL-YPF. Comunicado de prensa: el Grupo Petersen ejercita la opción de compra a Repsol de un 10\% de YPF. 2011. Mimeo.

SCHORR, M.; BARRERA, M.; KENNEDY, D.; PALERMO, H. Impacto socio-económico de YPF desde su renacionalización. Desempeño productivo e implicancias sobre los mercados laborales y el entramado de proveedores. Documento de Proyecto, Cepal-Oficina en Buenos Aires, 2015.

SCHORR, M. ; WAINER, A. La economía argentina bajo el kirchnerismo: de la holgura a la restricción externa. Una aproximación estructural. In: PUCCIARELLI, A.; CASTELLANI, A. (Coord.). Los años del kirchnerismo. La disputa hegemónica tras la crisis del orden neoliberal. Siglo Veintiuno, 2017.

SERFATI, C. El papel activo de los grupos predominantemente industriales en la financiarización de la economía. In: CHESNAIS, F. (Comp.). La mundialización financiera. Génesis, costo y desafíos. Losada, 1999.

SVAMPA, M.; VIALE, E. Maldesarrollo. La Argentina del extractivismo y el despojo. Katz Editores, 2014.

WHITTAKER, H. Premature financialization: a conceptual exploration. 2017. Disponible en: https://incas.hypotheses.org/. Acceso en: 20 Mayo 2018.

YPF. Memoria y estados contables al 31/12/2008 y comparativos. 2009. 


\section{Anexo metodológico}

Las estadísticas que sirvieron de base para la realización de esta investigación fueron generadas a partir de las bases de datos de la AFIP, el BCRA y el sistema Comtrade de Naciones Unidas.

La información tributaria utilizada está contenida en los Anuarios Estadísticos de la AFIP, en la sección "Ganancias de Sociedades" que resume las declaraciones juradas presentadas por las sociedades comerciales, es decir, comprende exclusivamente a la economía registrada. La información es publicada con una desagregación sectorial de 3 dígitos de la Clasificación Industrial Internacional Uniforme (CIIU) ${ }^{33}$. Posteriormente, ese cúmulo de datos fue agrupado con vistas a construir las ramas de actividad que resultaban de interés, de resultas de lo cual se llega a la siguiente definición sectorial:

- Agropecuario: códigos 011 a 032.

- Minería: códigos 051 a 099 (excepto 061, 062 y 091).

- Petróleo y gas: códigos 061, 062 y 091.

- Industria alimenticia: códigos 101 a 110.

- "Resto de la economía": todos los códigos excepto los comprendidos en las agregaciones anteriores y los códigos 639 a 669 (sector financiero).

Muchos de los conceptos contables son reportados por la AFIP distinguiendo entre casos con importes positivos y negativos, los cuáles fueron restados para obtener el importe neto correspondiente a las siguientes variables (entre comillas se destacan los términos utilizados por la AFIP):

- Resultado contable: suma de los importes de "resultado contable utilidad" menos suma de los importes de "resultado contable quebranto" de las empresas del sector.

- Resultado financiero: suma de los importes de "resultado por venta de acciones utilidad", "resultado por inversiones permanentes utilidad" y "resultados financieros utilidad" menos la suma de los importes de "resultado por venta de acciones pérdida", "resultado por inversiones permanentes quebranto" y "resultados financieros quebranto" de las empresas del sector.

- Resultado operativo: suma de resultado contable, "impuesto a las ganancias" y "resultados extraordinarios quebranto" menos la suma de "resultado financiero" y "resultados extraordinarios utilidad" de las empresas del sector.

(33) Hasta 2012 se utilizó la CIIU, Revisión 3; en los años siguientes se recurrió a la Revisión 4 a partir de las tablas de correspondencia proporcionadas por Naciones Unidas. 
- Patrimonio neto: suma de los importes de "patrimonio neto al cierre del ejercicio positivo" menos suma de los importes de "patrimonio neto al cierre del ejercicio negativo" de las empresas del sector.

- Inversión productiva: variable proxy calculada a partir de los bienes de uso (incremento interanual de la suma de los importes de "activo bienes de uso" de un sector).

- Activos financieros: suma de los importes de "activo inversiones" y "activo disponibilidades" de las empresas del sector.

- Inversión financiera: variable proxy calculada a partir de los activos financieros (incremento interanual de los activos financieros de un sector).

- Toma de deuda: variable proxy calculada a partir de "Pasivo Deudas" (incremento interanual de la suma de los importes de "pasivo deudas" de un sector).

Por su parte, la base de datos Comtrade fue utilizada para estimar los precios de transferencia como mecanismo de fuga siguiendo la metodología propuesta por Grondona y Burgos (2015). Para cada producto (a seis dígitos del Sistema Armonizado 2002) exportado por Argentina en cada año, se estimó la fuga vía precios de transferencia restando al valor FOB declarado por Argentina, el valor CIF declarado por el país importador, luego de corregirlo multiplicando por 0,9 para salvar la diferencia entre los valores FOB y $\mathrm{CIF}^{34}$. Por cada sector definido anteriormente, se agregaron los montos obtenidos para cada uno de sus productos exportados utilizando las tablas de correspondencia proporcionadas por Naciones Unidas. Para cada año, se conservó únicamente los valores negativos como indicador de fuga, descartando los positivos que son consecuencia de la corrección utilizada para salvar la diferencia entre los valores FOB y CIF.

Los datos correspondientes al giro al exterior de utilidades e intereses y la Formación de Activos Externos fueron obtenidos del Balance Cambiario del BCRA, convertidos a pesos a partir de la serie de tipo de cambio del Banco Mundial.

(34) Se trata de una estimación conservadora (que subestima la fuga vía precios de transferencia) porque la diferencia entre los valores FOB y CIF suele ser menor que $10 \%$. 